\title{
MR CLEAN: past the tipping point of clinical equipoise
}

\author{
Henry H. Woo, MD, ${ }^{1}$ Adam S. Arthur, MD, ${ }^{2}$ J Mocco, MD, ${ }^{3}$ Katie O. Orrico, JD, ${ }^{4}$ \\ John A. Wilson, MD, ${ }^{5}$ and Brian L. Hoh, MD, ${ }^{6}$ on behalf of the American Association of \\ Neurological Surgeons, Congress of Neurological Surgeons, and Cerebrovascular Section
}

\begin{abstract}
1'Departments of Neurosurgery and Radiology, Stony Brook University Medical Center, Stony Brook; ${ }^{3}$ Department of Neurosurgery, Mount Sinai Hospital, New York, New York; ${ }^{2}$ Department of Neurosurgery, Semmes-Murphey Clinic, Memphis, Tennessee; ${ }^{4}$ American Association of Neurological Surgeons/Congress of Neurological Surgeons, Washington, DC; ${ }^{5}$ Department of Neurosurgery, Wake Forest University, Winston-Salem, North Carolina; and ${ }^{6}$ Department of Neurosurgery, University of Florida, Gainesville, Florida
\end{abstract}

http://thejns.org/doi/abs/10.3171/2015.2.JNS15284

$\mathrm{T}$ HROMBOLYTIC therapy is no longer the only proven treatment for acute stroke. The National Institute of Neurological Disorders and Stroke tissue plasminogen activator (tPA) trial demonstrated that stroke patients could gain significant benefit from the administration of intravenous $\mathrm{tPa} .^{5,8}$ Following the publication of the Multicenter Randomized Clinical Trial of Endovascular Treatment for Acute Ischemic Stroke in the Netherlands (MR CLEAN), the same can be said for interventional thrombectomy for patients with emergent large-vessel occlusions (ELVOs). ${ }^{1}$ With an absolute risk reduction of $13.5 \%$ for functional outcome, the number needed to treat of 7.4 is similar to that for intravenous thrombolytic therapy, a remarkable result since $89 \%$ of the patients in MR CLEAN had already received intravenous $\mathrm{tPa} .{ }^{10}$

The authors of MR CLEAN are to be congratulated for their accomplishment, but their findings should not come as a surprise. The evidence to date is consistent and well documented upon careful review of the literature. ${ }^{7}$ Much has been made of the failure of prior trials to demonstrate the benefit of interventional thrombectomy. This failure is not surprising when evaluated in the context of the trial designs and the technologies used..$^{2-4,6}$ Most notably, interventional thrombectomy specifically targets ELVOshowever, 2 of the 3 trials did not require imaging confirmation of LVO, and thus included many patients without the index disease. Subset analysis of patients with preintervention CT angiography (CTA) confirming ELVO in the Interventional Management of Stroke Trial (IMS) III revealed substantial benefit for endovascular therapy. ${ }^{2}$ The
Local Versus Systemic Thrombolysis for Acute Ischemic Stroke (SYNTHESIS) trial did not even report the number of patients without ELVO at the time of angiography. ${ }^{3} \mathrm{Me}-$ chanical Retrieval and Recanalization of Stroke Clots Using Embolectomy (MR RESCUE) confirmed ELVO; however, that study was underpowered with its 118 subjects stratified across 4 treatment groups. ${ }^{6}$ Furthermore, these trials were limited by a lack of modern interventional technologies. Two already published prospective randomized trials had demonstrated the significant superiority of second-generation interventional devices over the interventional methods used in these 3 unsuccessful trials. ${ }^{9,11}$ Generalizing the conclusions of those trials to interventional thrombectomy for patients with ELVO was clearly premature.

Many research questions remain unanswered. For any procedure to be effective, the most important factor is patient selection. Much remains unknown about how best to use advanced imaging technology for acute stroke patients. Collateral cerebral circulation is different for each patient. There may be patients who can benefit from thrombectomy despite a delayed presentation from symptom onset. In addition, there may be patients who will not benefit despite early presentation, such as the patients in MR CLEAN, yet still suffer significant disabilities. Efforts to develop medical neuroprotective regimens that prolong tolerable ischemia times or facilitate subsequent recovery continue. And certainly, further improvements in technology, techniques, and systems of care will make thrombectomy even safer and more effective over time. 
The treatment of ELVO is not elective. Neurosurgeons and stroke teams are responding emergently to attend to these critically ill patients. In the United States, where physician reimbursement has been significantly undervalued by the Centers for Medicare \& Medicaid Services and outright denied by many third-party payers, there is little incentive to treat ELVO patients except the belief that it is the right thing to do. The MR CLEAN study confirms that it is no longer ethical to deny ELVO patients a treatment that can prevent disability or death.

Neurosurgeons and all health care professionals must now shift our efforts to identify how we can achieve better outcomes, improve access, and maximize patient selection. More than half of the patients with ELVO are still suffering significant disabilities even after successful recanalization. We must improve our systems of care to allow us to identify and triage ELVO patients better. Emergency responders and the general public have been trained to respond quickly to chest pain, facilitating a team approach to rapidly and efficiently identify and treat myocardial infarctions. Emergent large-vessel occlusion is likely to be even more time sensitive than acute myocardial infarction, and too many patients do not receive life-saving therapy because they are not identified in time. This is a massive and multifactorial problem that demands creative and very likely challenging solutions.

\section{References}

1. Berkhemer OA, Fransen PSS, Beumer D, van den Berg LA, Lingsma HF, Yoo AJ, et al: A randomized trial of intraarterial treatment for acute ischemic stroke. N Engl J Med 372:11-20, 2015

2. Broderick JP, Palesch YY, Demchuk AM, Yeatts SD, Khatri $\mathrm{P}$, Hill MD, et al: Endovascular therapy after intravenous t-PA versus t-PA alone for stroke. N Engl J Med 368:893903, 2013

3. Ciccone A, Valvassori L, SYNTHESIS Expansion Investigators: Endovascular treatment for acute ischemic stroke. $\mathbf{N}$ Engl J Med 368:2433-2434, 2013 (Letter)

4. Fargen KM, Neal D, Fiorella DJ, Turk AS, Froehler M, Mocco J: A meta-analysis of prospective randomized controlled trials evaluating endovascular therapies for acute ischemic stroke. J Neurointerv Surg 7:84-89, 2015

5. Hacke W, Kaste M, Bluhmki E, Brozman M, Dávalos A, Guidetti D, et al: Thrombolysis with alteplase 3 to 4.5 hours after acute ischemic stroke. N Engl J Med 359:1317-1329, 2008

6. Kidwell CS, Jahan R, Gornbein J, Alger JR, Nenov V, Ajani $\mathrm{Z}$, et al: A trial of imaging selection and endovascular treatment for ischemic stroke. N Engl J Med 368:914-923, 2013

7. Mocco J, Fiorella D, Fargen KM, Albuquerque F, Chen M, Gupta R, et al: Endovascular therapy for acute ischemic stroke is indicated and evidence based: a position statement. J Neurointerv Surg 7:79-81, 2015

8. National Institute of Neurological Disorders and Stroke rt-PA Stroke Study Group: Tissue plasminogen activator for acute ischemic stroke. N Engl J Med 333:1581-1588, 1995

9. Nogueira RG, Lutsep HL, Gupta R, Jovin TG, Albers GW, Walker GA, et al: Trevo versus Merci retrievers for thrombectomy revascularisation of large vessel occlusions in acute ischaemic stroke (TREVO 2): a randomised trial. Lancet 380:1231-1240, 2012

10. Saver JL, Gornbein J, Grotta J, Liebeskind D, Lutsep H, Schwamm L, et al: Number needed to treat to benefit and to harm for intravenous tissue plasminogen activator therapy in the 3- to 4.5-hour window: joint outcome table analysis of the ECASS 3 trial. Stroke 40:2433-2437, 2009

11. Saver JL, Jahan R, Levy EI, Jovin TG, Baxter B, Nogueira $\mathrm{RG}$, et al: Solitaire flow restoration device versus the Merci Retriever in patients with acute ischaemic stroke (SWIFT): a randomised, parallel-group, non-inferiority trial. Lancet 380:1241-1249, 2012

\section{Author Contributions}

Analysis and interpretation of data: Orrico. Drafting the article: all authors. Critically revising the article: all authors. Reviewed submitted version of manuscript: Woo, Arthur, Mocco, Wilson, Hoh. Approved the final version of the manuscript on behalf of all authors: Woo. Administrative/technical/material support: Woo, Arthur, Hoh.

\section{Correspondence}

Henry H. Woo, Stony Brook University Medical Center, Cerebrovascular Center, Hospital Level 4, Ste. 430, Stony Brook, NY 11794. email: henry.woo@stonybrookmedicine.edu. 